\title{
A Comparative Study Of Higher Education System In Pakistan And China
}

\author{
Yang Yingyu \\ Sichuan Normal University, China
}

\begin{abstract}
A comparative study of higher education was made to explore the collaboration between China and Pakistan. Budgetary allocations to all levels of education, both federal and provincial have also been presented and analyzed. A literature review of the publications consulted has also been provided. Wherever possible, data has been gathered from government websites and other publications. The study explores the policy, mechanism to find the similarities and dissimilarities between the two countries and search for potential education collaboration between the two countries.
\end{abstract}

Keywords : Higher Education, Educational Policy, Comparative Study

$$
\begin{aligned}
& \text { تلخيص }
\end{aligned}
$$

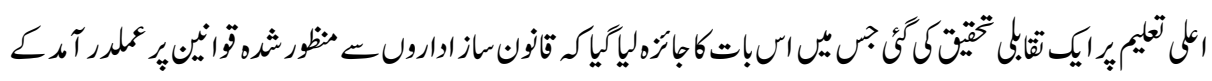

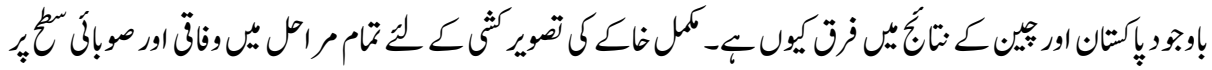

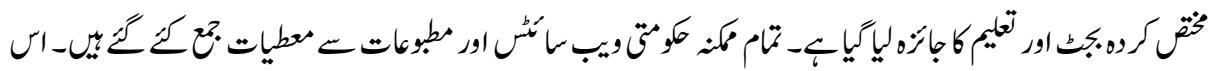

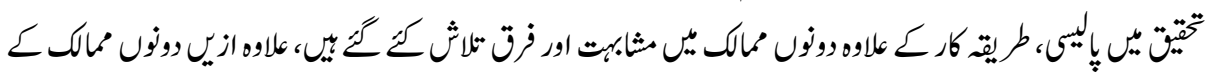

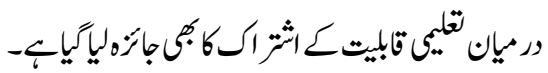

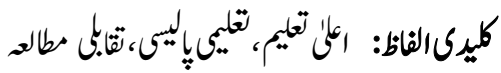

\section{Introduction}

As is known to all, relations between China and Pakistan has been described as that of an "all-weather friends". China and Pakistan have shaped a paradigm of neighbor-toneighbor relations. Their time tested friendship, described as "higher than the mountains and deeper than the oceans", is not just a bunch of words. China and Pakistan have fostered a very close relationship over the decades, and ties between the two countries date back to 1950 when Pakistan joined a small handful of nations in recognizing the People's Republic of China. During these sixty four years, China constantly continues to enhance solidarity and cooperation with Pakistan; there has been an increase mutual 
understanding and trust to strengthen mutual help and support. At the same time, both sides share the benefits of ongoing developments. China and Pakistan's cooperation has been very close in a range of fields. Actually, areas of cooperation include issues such as economics, health, education, regional conflicts, ethnic conflicts and natural disasters. The relationship is indeed a geopolitical keystone for both countries. Pakistan remains China's closest friend both in South Asia and among Islamic countries. With the developing of the close cooperation in so many fields, China and Pakistan are likely to explore collaboration in the field of education. The education system has a vital role in each country, although each country has a different system. To what extent, can we have common interests. This study explores the policy and mechanisms to find the similarities and dissimilarities between the two countries and search for possibility of collaboration in education between the two countries.

\section{China-Pakistan Relations}

Globalization has manifested itself not only in economic matters and finance, but also in almost all aspects of contemporary cultural and intellectual life. "Globalization calls to the attention of literary and cultural studies scholars that the recent popularization of the Chinese language and culture worldwide should also be taken into serious consideration, for it will contribute a great deal to the remapping of the world language system and the rewriting of literary culture by pointing out a new orientation of literary historiography. In this aspect, Chinese literature, which flourished in ancient times but was later longrepressed and marginalized, will certainly contribute a lot to the realization of world literature along with the current popularization of the Chinese language." (Wang, 2010) It is indeed a fact that Chinese has grown to become another major world language besides English.

Over the years, subsequent to 1951, China and Pakistan have gone through thick and thin circumstances and have developed the type of relationship referred to as an all-weather friendship which has withstood the test of time and is maturing day by day. In recent years, a comprehensive cooperation between China and Pakistan has been developing in a more standardized and legal direction. Compared with traditional forms of bilateral ties, China-Pakistan relations go well beyond economic and trade links and are closely allied to the strategic field. The two countries have had extensive and close cooperation in several areas that would otherwise be deemed sensitive to a nation's core interests, including the military and nuclear energy. Both sides have also cooperated closely in combating terrorism in central Asia, which poses a grave threat to peace and stability in the region. Lutfullah Mangi, a professor of international relations at the university of Sindh, has said that "Pakistan-China relations are linked in four areas: political relations; military cooperation; trade and economic relations; and people-to-people contact and cultural relations." (Mangi, 2010) Among the four areas, the establishment of the 
Pakistan-China Think Tank in September 2009 promises to be a good beginning. The focus of the Think Tank is devoted to promoting, strengthening and expanding PakistanChina relations in different areas, such as security, trade, education and culture. Currently, there are three Confucius institutes in Pakistan. The Confucius institute in Islamabad and the Confucius institute in Karachi and the Confucius Institute in Faisalabad, which was established in 2014. I. The Confucius Institute in Islamabad Pakistan was established in 2007. It is the first Confucius Institute in the Islamic world. It is not difficult to discover that Chinese learning is popular in Pakistan; the two countries have started to engage cooperatively in education. In order to broaden this cooperation, we need to observe more educational details concerning higher education in the two countries. According to the statistics from China Education Yearbook in 2011, "Annual foreign students who study in China exceeded 290,000. According to national statistics, the number of foreign students in India and Pakistan ranked eight and nine and the number of overseas students reached 9.370 and 8.516 respectively. In 2010, the rankings are 8 and 10, with the number of 9.014 and 7.406 students respectively, in recent years, due to the ease of Chinese university admission and relatively cheaper tuition than European countries, especially general medicine degrees in both internal and external courses, China is becoming one of the preferred destinations for overseas students of South Asian countries." (China Education Year Book, 2011)

\section{The Significance of Education}

Education is a basic human need for socio-economic development and basic education is a fundamental human right providing us with the foundation for further development. The founding fathers of Pakistan realized that the future of this nation depended on a productive pursuit of knowledge through education. In his message to the first Education Conference in November 1947, The Father of Pakistan sets the guidelines in his detailed message: "Under foreign rule for over a century, in the very nature of things, I regret, sufficient attention has not been paid to the education of our people, and If we are to make real, speedy and substantial progress, we must bring our educational policy and program on the lines suited to the genius of our people, consonant with our history and culture and having regard to the modern conditions and vast developments that have taken place all over the world." (Tahir, 1980)The future of our State will and must accordingly depend upon the type of education we give to our children, and the way in which we bring them up as future citizens of Pakistan. We should try, by sound education, to instill into them the high sense of honor, integrity, responsibility and selfless service to the nation. There is an immediate and urgent need for giving scientific and technical education to our people in order to build up our future economic life and to see that our people take to science, commerce, trade and particularly well-planned industries. We should not forget that we have to compete with the world which is moving very fast in this direction." Most educators have realized the emergency status of 
education in Pakistan, but the facts are not so encouraging. "The Education Sector in Pakistan suffers from insufficient financial input, low levels of efficiency for implementation of programs, and poor quality of management, monitoring, supervision and teaching." (Memon, 2007)

The Chinese Government gives priority to the development of education. It is particularly concerned with financial investment in education and the introduction of policy. The data released by Chinese government in May, 2013 shows that Chinese expenditure for education relative to GDP is for the first time up to international standards. Analysts say that it is an important milestone for China in its transition from a big educator to a powerful one. According to the Ministry of Finance, the national public expenditure statement of 2013 shows that expenditure for education in 2013 is 2.2trillion, which accounts for $95.5 \%$ of budget, also $123.6 \%$ of actual budget. Amongst this, spending on general education is 1.7 trillion, $79.5 \%$ of spending on education. Regional public expenditure statement of 2013 shows that actual budget for education is 2.1 trillion, 103.7\% higher compared with the last year. Fiscal balance in August 2014 indicates that education expenditure is 1.3 trillion, with year-on-year growth of $11.1 \%$, contributing about $14.2 \%$ of national spending.

The scale of higher education has been developing steadily. In 2012, there are a total of 2790 high schools across the country, which is more than the previous year. Among them, 2442 are regular institutions of higher learning; this represents 33 more schools than that of last year. There are 348 adult colleges and universities, 5 less than last year; the various forms of higher education amounts to a total of 33.3 million people, an increase of 1.6 million over the previous year, this represents a growth of 5.0\%. All these statistics are from China Education Situation-2012 National Education Career Development, issued by MOE.

In 2010, Ministry of Education issued the China's Medium-and Long-Term Talent Development Plan (2010-2020). It proposed strategic goals for education, that is, to basically achieve the modernization of education by 2020; formulate a learning-oriented society; and an increase in the effectiveness of human resources. It requires raising universal schooling to a higher level, developing education equality in relation to the entire population, providing a high-quality education, constructing a complete system of life-long education and perfecting an active education system. As for higher education, it specifically proposed that we should encourage those engaged in prominent research open up to the world, support them to join and set up international academic collaboration organizations, support them to build joint facilities with overseas education and research organizations at a high level, increase steps to introduce world-class universities, cultivate a galaxy of elite innovation talents, establish a compendium of world-class curriculum, achieve a set of leading original achievements, and make every 
efforts to strengthen comprehensive national effectiveness. In chapter 16, it also gives details about how to expand the process of opening up education. It requires us to increase the number of international students, raise the amount of sponsorship by the Chinese government, put the major emphasis on the students form developing countries, optimize the situation for international students studying in China. There is also the necessity to organize pre-education for foreign students, to increase majors taught in English in institutes, and to improve the quality of education for international students.

In order to promote mutual understanding, cooperation and exchange between China and other countries, the Chinese government has set up a series of scholarship programs to sponsor international students, teachers and scholars for degree studies (bachelor, master or $\mathrm{PhD}$ ) or academic research in China. The Chinese Government Scholarship supports the following 7 programs (Bilateral Program; Chinese University Program; Great Wall Program; EU Program; AUN Program; PIF Program; WMO Program). Academic programs of Science, Engineering, Agriculture, Medicine, Economics, Law, Management, Education, History, Literature, Philosophy and Arts in 252 designated Chinese universities are available to scholarship winners.

\section{Government Policies}

The World Education Forum (26-28 April 2000, Dakar) adopted the Dakar Framework for Action, referring to Education for All (EFA). In response to the Dakar Forum commitments, Pakistan developed a comprehensive National Plan of Action (NPA) on Education for All, devised as a long-term framework (2001-15), to be executed in three five-year phases, focusing on early childhood education, universal primary education and adult literacy as three of its focal points. This plan was developed and endorsed by the first Poverty Reduction Strategy Paper (PRSP I: 2003-2006) but could not be executed due to shortage of finances. Under the EFA plan and in coherence with the constitution and key policy framework, provinces will be introducing projects for the enhancement of the education sector. For the children, it required that the government should expand comprehensive early childhood care and education and ensure that by 2015 all children have access to complete, free, and compulsory primary education of good quality. For the adults, there is the need to achieve a 50\% improvement in adult literacy by 2015 and eliminate gender disparities in primary and secondary education by 2005 and achieve gender equality in education by 2015 . Especially, it emphasis more focus on ensuring girls' full and equal access to and achievement in basic education of good quality. The White Paper on Education was disseminated end December 2006, as a pre-policy document to stimulate a discussion of major policy issues concerning education in Pakistan. 
In China, the Order No. 7 of the President of the People's Republic of China was issued on August 29, 1998, which concludes the Higher Education Law of the People's Republic of China". The Article 12 in general provisions(Chapter one) says "The State encourages collaboration between higher education institutions and their collaboration with research institutes, enterprises and institutions in order that they all can draw on each other's strengths and increase the efficiency of educational resources. The State encourages and supports international exchange and cooperation in higher education." and the article 36 in fourth chapter states "Higher education institutions shall, in accordance with the relevant regulations of the State, act on their own in conducting exchange and co-operation with higher education institutions outside of the territory of China in the fields of science, technology and culture." (http://www.moe.edu.cn/publicfiles/business/htmlfiles/moe/s7566/201309/156899.html).

The Chinese Government attaches a great importance to inter-school cooperation, and also encourages universities to intensify international cooperation. Besides this, in order to ensure that poorer students get a higher quality education, The State has established scholarships and encourages higher education institutions, enterprises, institutions, public organizations or groups and individuals to establish scholarships in a variety of ways in accordance with the relevant regulations of the State.

The State has established work-study funds and student loans for students of higher education institutions and encourages higher education institutions, enterprises, institutions, public organizations or groups and individuals to establish stipends in a variety of ways to provide assistance for students who come from families with financial difficulties.

\section{Comparison of Different Educational Levels in China and Pakistan}

"Education in Pakistan can be roughly divided into: a. Public Sector (Government Institutions); b. Private Sector (ranging from schools for the poor to the very rich); and c. Madrassas (schools to impart religious education). There are 256,088 educational institutions of all categories in Pakistan, with a total enrollment of 37,462,884 students." (Mahmood, 2012)

\section{Degree Colleges}

Undergraduate education (degree colleges) is an education level taken in order to gain one's first tertiary degree (except for an associate's degree). Undergraduate education consists of post-secondary education up to the level of a bachelor's degree. In Pakistan the Graduation system is classified into two Undergraduate (UG) and Postgraduate (PG) Systems. The undergraduate takes two or four years to complete his/her degree. The two 
year undergraduate programs are mostly in the fields of arts, humanities, science etc., and the four year programs are mostly in the fields of technology, engineering, pharmaceutical sciences, agriculture etc. However, for medicine, law and architecture, the period has been five years. In Pakistan, 1,558 degree colleges are providing services in the education system. Out of these 1,154 (74\%) are in the public sector, whereas 404 $(26 \%)$ are in the private sector. The total enrollment at degree college stage i.e. in grades 13 and 14, is 0.431 million. Out of these students at this stage of education, 0.385 million $(89.36 \%)$ are completing their degrees in the public sector, whereas, the rest of the 0.046 million $(10.6 \%)$ students are in the private sector. The total boys enrollment at degree colleges stage is 0.213 million (49.4\%), whereas, the girls enrollment is 0.218 million $(50.58 \%)$. The total teachers at degree colleges level are 36,349, out of which 30,995 $(85 \%)$ are in the public and $5,354(15 \%)$ are in the private sector. The percentage distribution of teachers at degree level is shown. There are 20,168 (55\%) male teachers and 16,181 (45\%) female teachers. A vocational university, sometimes called professional university or applied technological university college of higher vocational studies, is an institution of higher education and with provision for research, which provides both tertiary and sometimes quaternary education and grants academic degrees at all levels (bachelor, master, and sometimes doctorate) in a variety of subjects. In China, 1,297 vocational colleges provide their services in the education system. They enroll local high school graduates for degree programs who pay fees and commute to school. Admission is based on a nationwide entrance exam. Normally VU students have lower scores than those who are admitted into provincial and national institutions. Unlike those who attend a provincial or national institution, a job is not assigned to a VU student at graduation. The total students in vocational school are 9,642,267, out of which 4,998,527 (52\%) are female students and 4643740(48\%) are male students. The technical school students in web-based education are 3,701,414, and there are 1770409 female students which accounts for 49.8\%. Male technical school students in web-based education are $1931005(50.2 \%)$. The above statistics prove that the percentage distribution of students in vocational schools remains basically the same. The proportion of girls is slightly higher than that of the boys. Most vocational universities found it difficult to recruit enough qualified full-time faculty personnel, so they employ part-time faculty members, who usually focus on practical skill training. The total educational personnel at vocational school are 622,425, there are 423,381 full-time teachers amongst them, that is, and the staff to students' ratio is one to sixteen. Current master students in China number $1,719,818$ and undergraduate students number $14,270,888$. There are $5,331,770$ in private college. $^{2}$

\section{Universities}

University education is a critical component of human development worldwide. It provides not only the high-level skills necessary for every labor market but also the 
training essential for teachers, doctors, nurses, civil servants, engineers, humanists, entrepreneurs, scientists, social scientists, and a myriad of other personnel. It is these trained individuals who develop the capacity and analytic skills that drive local economies, support civil society, teach children, lead effective governments, and make important decisions which affect entire societies. There are a total of 135 universities providing their services in both the public and the private sector of education. Out of these universities $76(56 \%)$ are working under the umbrella of public sector, whereas 59 (44\%) are working under the supervision of private sector as reflected.

The total enrollment in the universities, i.e., at post graduate stage, is 1.108 million. Out of this enrollment 0.949 million (86\%) students are enrolled in public universities, whereas, 0.159 million (14\%) students are studying in private universities. The percentage distribution of universities enrollment by sector counts 56\% (Public) and 44\% (Private). The distribution percentage of universities is $86 \%$ (Public) and 14\% (Private) sector. The distribution of Universities' Enrollment in the Public and Private Sector is: total male enrollment is 0.586 million (67\%), whereas, the female enrollment is 0.521 million (33\%). The total number of teachers in the universities is 63,557, out of which $50,260(79 \%)$ are in the public and 13,297 (21\%) are in the private sector.

Pakistan's spoken language is English, for most Pakistani students, their English proficiency is better than their Chinese capacity. Therefore, offering English classes to Pakistan international students is an undoubted help for them so that they can study Chinese faster and more efficiently, and it is more beneficial to them to increase their knowledge. Currently, the government is gradually improving English teaching courses; English classes are provided at the undergraduate level to international students whose majors are medical science. Actually, in order to attract students from all over the world. The Chinese government and schools are actively thinking reform countermeasure to solve students' learning difficulties. Figure 1 is the scale of enrollment for undergraduate clinical medicine programs taught in English for International Students from 2011 to 2014. The statistics are provided by the Ministry of Education of P.R.C. (http://www.moe.edu.cn/publicfiles/business/htmlfiles/moe/moe_2804/index.html)

"Professional English teaching has a strong appeal for foreign students in China, students in Africa and Central Asia countries and regions are especially in favor of it, it cannot limited by the language learning process. According to the research, the average age of international students is between 18 22. Being taught in English provides the basis and the opportunity for international students to find a job." (Mao, 2014) 


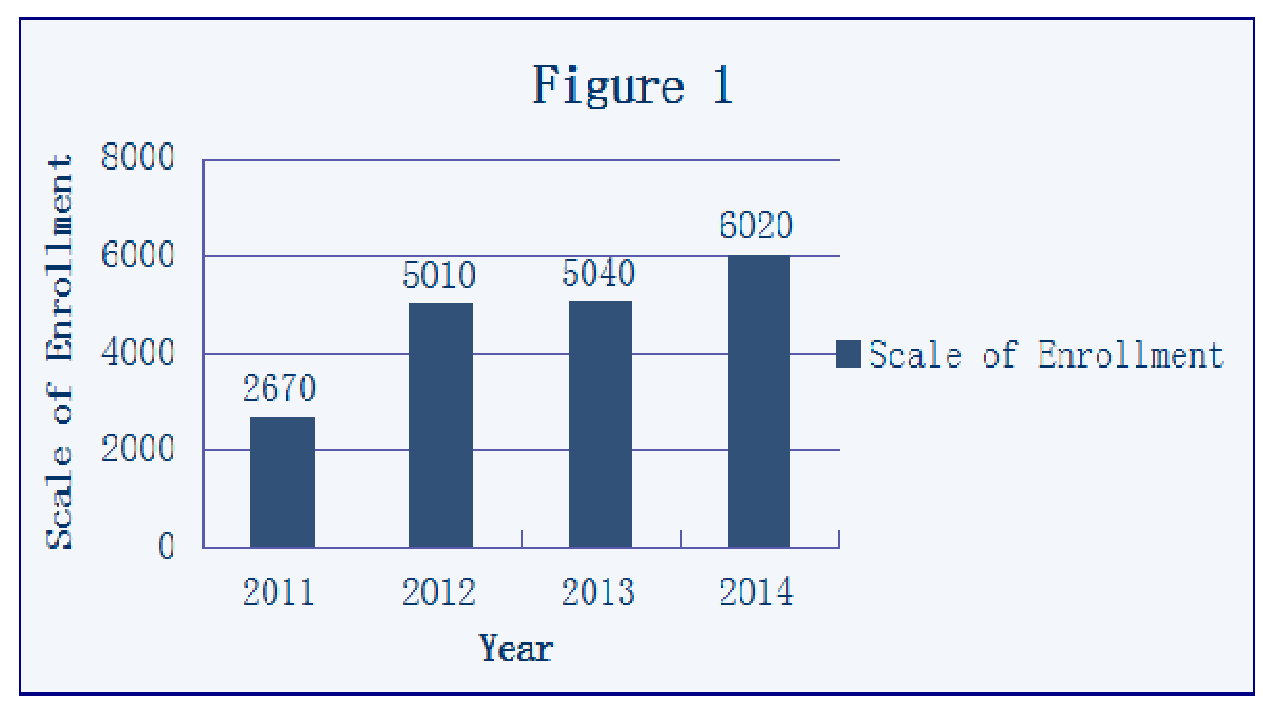

From figure 1, we can see that the scales of enrollment for overseas students are gradually increasing year by year; the courses taught in English provide a major step in international education. The relevance of education to global competitiveness can be seen in the table from the Global Competitive Index (GCI), given in the following page. Pakistan has been compared with its major competitors in an international context. (Higher the number assigned to a pillar, the lesser the performance.)

GCI Pillars and Comparators

\begin{tabular}{|l|l|l|l|l|l|l|}
\hline $\begin{array}{l}\text { Pillars/ } \\
\text { Parameters }\end{array}$ & Pakistan & Bangladesh & China & India & Malaysia & $\begin{array}{l}\text { Sri } \\
\text { Lanka }\end{array}$ \\
\hline 1. Institutions & 79 & 121 & 80 & 34 & 18 & 82 \\
\hline 2.Infrastructure & 67 & 117 & 60 & 62 & 23 & 76 \\
\hline 3.Macro-economy & 86 & 47 & 50 & 88 & 31 & 110 \\
\hline 4.Health and Primary & 108 & 90 & 55 & 93 & 42 & 36 \\
\hline $\begin{array}{l}\text { 5.Higher Education \& } \\
\text { Trg. }\end{array}$ & 104 & 108 & 77 & 49 & 32 & 81 \\
\hline $\begin{array}{l}\text { 6.Market } \\
\text { Efficiency }\end{array}$ & 54 & 83 & 56 & 21 & 09 & 71 \\
\hline $\begin{array}{l}\text { 7.Technological } \\
\text { Readiness }\end{array}$ & 89 & 114 & 75 & 55 & 28 & 83 \\
\hline $\begin{array}{l}\text { 8.Business } \\
\text { Sophistication }\end{array}$ & 66 & 96 & 65 & 25 & 20 & 71 \\
\hline 9. Innovation & 60 & 109 & 46 & 26 & 21 & 53 \\
\hline
\end{tabular}

(Source: The State of Pakistan's Competitiveness 2007, Competitive Support Fund, USAID, Ministry of Finance, Government of Pakistan, 2007.) 


\begin{tabular}{|l|c|c|c|c|c|c|c|c|c|}
\hline Country & $\begin{array}{c}\text { HDI } \\
\text { Ranking }\end{array}$ & HDI & LED & EYS & MYS & EI & II & HI & GII \\
\hline China & 101 & 0.687 & 73.5 & 11.6 & 7.5 & 0.623 & 0.618 & 0.843 & 0.209 \\
\hline Pakistan & 145 & 0.504 & 65.4 & 6.9 & 4.9 & 0.386 & 0.464 & 0.717 & 0.573 \\
\hline
\end{tabular}

(Source : UDP Human Development Report 2011.)

HDI: human development index; LEB: life expected years of schooling; ETS: expected year of the schooling; MYS: mean years of the schooling EI: education index; II: income index; HI: health index; GII: gender inequality index.

From the above table, we can see that the gender inequality index in Pakistan is higher than that of China. China's education index is higher than that of Pakistan. In Masud paper Radicalization of Opposition to Girls' Education in Pakistan Socio-Religious Analysis (Masud, 2011), he presented a summary of the findings of several reports on the issues relating to girls' education in Pakistan, which indicates that girls are not given enough education, so the percentage of illiteracy among Pakistani girls is higher than that of the boys. In contrast to this, according to the number of female students of schools by Type and level posted by The Ministry of Education of P.R.C. the numbers of female students are nearly close to the number of male students, both in compulsory education or in the higher education sector. In 2014, the Ministry of Education issued a list of regular colleges and universities in China, the total number being 2,246. This list involves different fields, such as, medicine, engineering, education, computer, language, etc. According to the educational statistics, there are 1,145 regular HEIs (higher education institutes), out of which 303 are independence institutions. There are 1,627,642 educational personnel, out of which 1,013,957 are full time teachers. ${ }^{3}$ (http://www.moe.edu.cn/publicfiles/Business/htmlfiles/moe/s7566/

01309/156899.html)

\section{Higher Education in Pakistan and China}

Good quality, merit-oriented, equitable and efficient higher education is the most crucial instrument for translating the dream of a knowledge-based economy into reality. The tertiary sector contributes as well in the attainment of social goals such as developing civic responsibility, social cohesion and a more tolerant society. For this reason, in addition to the traditional functions of producing skilled labor force and crafting new knowledge through research, a third is being added, throughout the world, that of service to society.

The Higher Education Commission (HEC) was created to serve as the apex body for all matters pertaining to policy, plans, programs, standards, funding and oversight of higher education in the country and also to transform the higher education sector to serve as an 
engine of growth for the socio-economic development of the country. The HEC has the responsibility to formulate policies, guiding principles and priorities for higher education. It is also responsible for the institutions for promotion of socioeconomic development of the country, the funding of higher education institutions, accreditation and quality assurance of academic programs and the preparation of plans for the development of higher education. It can empress its opinion on all matters relating thereto.

\section{Challenges}

Provision of quality education requires a mechanism for internal and external evaluation of quality parameters. In this regard it is necessary to ensure that program and university accreditation mechanisms instituted are compatible with international practices and provide complete transparency of operation. The scale, quality and institutional arrangements of the higher education sector must be able to support and encourage innovation in the economy and provide domestic and international funding support. The challenge is to enhance the $R \& D$ capacity to achieve knowledge transmission to the productive sector through university-industry partnerships. On the governance side, the academic and administrative management of Colleges remains an unresolved issue since the degrees are awarded by the universities while the administrative control of colleges themselves lies with the provincial governments. In China, teachers' job satisfaction relating to flexibility and autonomy, teaching and research has been influenced by higher education changes in respect of enlarged class size, long working hours, increased evaluation and assessment and stresses.'(Bhutta, 2013)

While preparing a response to the challenges faced in transforming the higher education sector in Pakistan to respond to domestic and global socio-economic challenges we need to recognize several things. The first one is faculty development, which cannot be viewed in isolation and must be considered together with the development of an environment conducive to academics. The higher education system and institutions must accord high priority to ensuring the quality of services and quality of outcomes. In the modern global knowledge-economy, employers increasingly look to universities and colleges to deliver a well-educated workforce that they require in the form of articulate, flexible, and readily employable graduates in order to remain competitive. Universities and institutions of higher learning and research play a catalytic role in the economic development of the region in which they are located. Movements in the global knowledge-society will require universities to develop into diverse, flexible, self-analytical and adaptable enterprises. For the graduates, they must have the ability to communicate effectively both in writing and in reading. The realization of the strategic vision and implementation of proposed policy actions will require the availability of adequate financial resources. It is imperative to enhance the funds available to the education sector to that of $7 \%$ of GDP by 2015 as well as to enhance the proportion of this budget available to the higher education 
sector to $20 \%$ of the education budget. The Policy endorses the main lines of the Medium Term Development Framework (2005-10) of the Higher Education Commission, while suggesting additional action that are consistent with the Framework.

\section{A Summary of Flaws in Existing System, Structure and Culture that Hinders Quality in Research}

The higher education system is not improving sufficiently better, in spite of strides made in the past decade. Enrollment stands at about 8\% (including two-year colleges) of the age cohort, a statistic that compares unfavorably with countries such as India at $18 \%$ and Malaysia at $42 \% .3$. The problems in this system are legion: the low quality of faculties, low student motivation, rote learning and an outdated curriculum, there is poor student discipline in public universities, lack of funding, lack of research, and so forth. As a result, a large majority of Pakistani graduates emerge from universities without the technical or social skills needed for them to be strong contributors in the workplace or society, either in Pakistan or on the global stage.

These problems are not new or unknown, and Pakistani governments have tried, with questionable resolve, to respond. Pakistan in fact has a long history of failed reforms and educational development plans. As early as 1959, the National Commission on Education produced a report that outlined the problems in Pakistan's educational system and recommended reforms. By and large, the problems identified in that report remained unaddressed and have persisted through the Government of Pakistan's educational policies of 1970, 1972, 1979, 1992, and 1998. These problems have also persisted despite period of more than eight five-year development plans that, among broader development efforts, were aimed at resolving the problems in the education sector. The long neglect has made these problems graver than ever before. In a world in which many countries (including the developing world) are moving ahead quickly in terms of their economic and social development, Pakistan risks falling ever further behind if it cannot educate its young people effectively. Moreover, the challenges to Pakistan's education system are about to multiply, given that the number of young people is projected to rise significantly in the coming decades. The current education system in Pakistan is for the most part unable to educate the existing and the prospective large numbers of students so that they are fully functionally literate. It is imperative that they are able to contribute productively to the economy, and are fully aware citizens, able to take part in overcoming the country's vast development challenges.

\section{Conclusions/ Recommendations}

The government has made a good education policy, and the aims and objectives of the government are directed to increasing the literacy rate of the country and development of 
education sector within five years. The government has made targets and defined the policy to be implemented. The major problem which the government faces is the implementation process. Whist government has set good policy goals, the implementation of policies is not up to the mark and the main reason for poor implementation is the lack of institutions to deal with this, the implementation process of the government is ineffective which makes the policies of the government ineffective thus the desired results are not achieved. The policy designed is good and will only be successful if is implemented effectively

\section{End Notes}

1. Higher Education Law of the People's Republic of China, adopted at the Fourth Session of the Standing Committee of the Ninth National People's Congress on August 29, 1998, promulgated by Order No. 7 of the President of the People's Republic of China on August 29, 1998 and take effect on January 1, 1999.

2. all these statistics are from China Education Situation-2012 National Education Career Development, issued by Ministry of Education.

3. All the statistics are from the website of Ministry of Education in China. (http://www.moe.edu.cn/publicfiles/business/htmlfiles/moe/s7566/01309/156899. html

\section{References}

Bhutta, Zahra Masood (2013). Working design and performances of university teachers: the comparative analysis between China and Pakistan [D]. Shanxi : North West Agriculture and Forestry University. P, 10.

Mahmood, Abida (2012). The role of schools in building a peaceful society in Pakistan. IPEDR. Singapore: IACSIT Press.

Mangi, Lutfullah(2010). Pakistan and China: An Excellent Model for Relations Between Neighboring Countries. Contemporary International Relations, 6, p. 106.

Mao Yunhua (2014). 'Stimulation of Full-English Teaching for International Students'. Academic Research, 2, p. 67.

Masud(2011). "Radicalization of Opposition to Girls' Education in Pakistan SocioReligious Analysis" available at http://www.maruf.org/?p=211\#_ftn8, 2011-54/2014-9-28 
Memon, Ghulam Rasool(2007). 'Education in Pakistan: The Key Issues, Problems and The New Challenges'. Journal of Management and Social Sciences, p. 48.

Ministry of Education, China(2007). A White Paper(Revised)-Document to debate and finalize the national education policy.

Ministry of Education(2013). China education situation-2012 national education career development.

Ministry of Education(2013)"Number of Schools, Educational Personnel and Full-time Teachers by Type and Level" available at http://www.moe.edu.cn/publicfiles/ business/htmlfiles/moe/s7566/201309/156899.html

Ministry of Finance(2007). The State of Pakistan's Competitiveness.

Tahir, Pervez (1980). Economic and Social Thinking of the Quaid-i-Azam. Lahore: Research Society of Pakistan, University of the Punjab, p. 39.

UDP (2011). Human Development Report.

Wang Ning (2010). 'Global English(es) and Global Chinese(s): toward rewriting a new literary history in Chinese'. Journal of Contemporary China, 19, pp. 159-160.

Dr. Yang Yingyu is Professor of Comparative Literature and Vice Director of office of International Education, Vice Dean of College of Global Education, Sichuan Normal University, Sichuan, China. 